\title{
ABSTRACT \\ IMPACT OF AN ATRAZINE-BASED HERBICIDE ON AN AGROBIONT WOLF SPIDER
}

\author{
by Jake A. Godfrey
}

For animals that live in association with humans, a key ecological question is how anthropogenic factors influence their behavior and life history. While major negative effects are obvious, subtle non-lethal responses to anthropogenic stimuli may provide insight into the features that lead to the success of species that thrive in habitats heavily impacted by humans. Here I explored the influence of the herbicide atrazine on the behavior and various life history traits exhibited by a wolf spider that is found in agroecosystems where this herbicide is commonly applied. In my first experiment, exposure to atrazine altered activity patterns of this spider. In my second experiment, exposure delayed maturation and increased the probability of spiders having a faulty molt. Atrazine also decreased the probability of producing an egg sac after mating, increased mass of egg sacs that were produced, and negatively impacted adult lifespans. These results suggest that the atrazine-based herbicides that are routinely applied to agricultural fields result in altered behavior and life history traits of these spiders and may therefore influence the community of predators and their effects on the food web in complex ways. 
IMPACT OF AN ATRAZINE-BASED HERBICIDE ON AN AGROBIONT WOLF SPIDER

\author{
A Thesis \\ Submitted to the \\ Faculty of Miami University \\ in partial fulfillment of \\ the requirements for the degree of \\ Master of Science \\ by \\ Jake A. Godfrey \\ Miami University \\ Oxford, Ohio \\ 2017 \\ Advisor: Ann L. Rypstra \\ Reader: Michelle D. Boone \\ Reader: Alan B. Cady \\ Reader: Ann L. Rypstra
}

C2017 Jake A. Godfrey 
This Thesis titled

\title{
IMPACT OF AN ATRAZINE-BASED HERBICIDE ON AN AGROBIONT WOLF SPIDER
}

by

\author{
Jake A. Godfrey \\ has been approved for publication by
}

The College of Arts and Science

and

Department of Biology

Ann L. Rypstra

Michelle D. Boone

Alan B. Cady 


\section{Table of Contents}

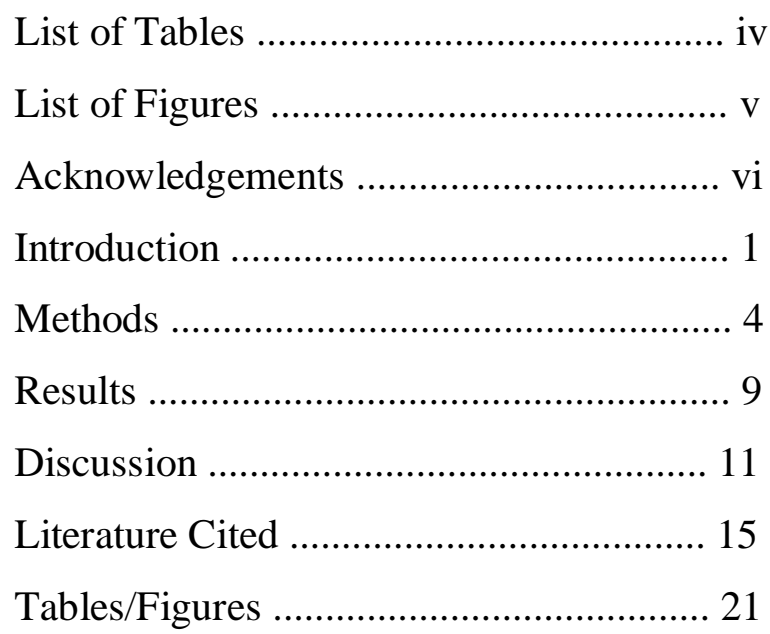




\section{List of Tables}

Table 1 ........................................... 21

Table 2 .......................................... 22

Table 3 ............................................ 23

Table 4 .......................................... 24

Table 5 ........................................... 25

Table 6 ............................................ 26

Table 7 ........................................... 27

Table 8 ........................................... 28

Table 9 ............................................ 29

Table 10 .......................................... 30 


\section{List of Figures}

Figure 1 ...................................... 31

Figure 2 .................................... 32

Figure 3 ....................................... 33

Figure 4 ..................................... 34

Figure 5 ................................... 35

Figure 6 ...................................... 36 


\section{Acknowledgements}

I would very much like to thank my advisor, Dr. Ann Rypstra, not only for being an amazing advisor, but being an amazing person and friend. A lot of great insight and ideas came from her and my fantastic committee, Dr. Michelle Boone and Dr. Alan Cady. Moral support and suggestions came from my fellow graduate labmates. I also owe a great deal to the army of hardworking undergrads that keep the lab running. I would also like to thank Miami University for continued support in my studies as well as providing funding for this project. 


\section{Introduction}

Chemical communication is foundational to the behavior of the majority of animals and humans (Wyatt, 2014). Chemicals such as pheromones aid in the location and evaluation of potential mates (Cinková and Policht, 2015; Meyer-Lucht, Poschadel, and Plath, 2006) and provide information about potential competitors (Lane et al., 2015). Outside of conspecifics,

these cues also allow predators and parasitoids to locate prey and hosts (Holding et al., 2016; Li et al., 2015). Prey in return may respond appropriately to cues left by predators in order to minimize risk (Castorani and Hovel, 2016; Wilgers et al., 2014). Similar to these external cues, the endocrine system of animals produces and responds to many chemical cues (hormones), which influence many physiological processes including reproduction, sexual differentiation, development, and regulation of metabolism (Nussey and Whitehead, 2001). With the wide array of responses evoked by these chemical signals, it is important to understand potential factors that could alter or mask this information in nature.

There is a large body of evidence indicating that anthropogenic chemicals can disrupt natural chemical information transfer both internally and externally. Some chemicals, such as pesticides, are classified as endocrine-disruptors for their ability to mimic or block hormones when absorbed into the body where they disrupt natural functions (Schug et al., 2011). For example, triazoles (a group of fungicides), have been thoroughly studied as endocrine-disruptors. Triazoles have been shown to alter thyroid hormone levels in zebrafish (Yu et al., 2013), impact reproductive development of rats in utero (Taxvig et al., 2007), and disrupt testosterone homeostasis in rats (Goetz et al., 2007). Malathion, a commonly used acetylcholinesterase inhibitor, is also an endocrine-disruptor, reducing levels of thyroxine, growth hormone, testosterone, and estradiol-17 $\beta$ in freshwater catfish (Lal et al., 2013).

Playing similar roles but extending outside the body, some anthropogenic chemicals impact the transfer of chemical information between organisms, acting as "info-disruptors" (Lürling and Scheffer, 2007). For instance, tadpoles of the Cuban tree frog, Osteopilus septentrionalis, that are exposed to an herbicide cannot detect and respond appropriately to predator cues (Ehrsam et al., 2016). Crayfish, Cambarus bartonii, also have been found to have difficulty localizing a food source in presence of sublethal copper concentrations (Sherba et al., 2000). Some insecticides can impair chemical communication in the plankton communities by 
disrupting kairomones (Hanazato, 1999). Even fertilizers with high nitrogen content have been shown to inhibit the production of male olfactory cues in newts (Triturus helveticus), causing them to be less attractive to potential mates (Secondi et al., 2009). Through studies such as these it has become evident that anthropogenic chemicals often have adverse effects on animals extending far beyond lethality.

It is often difficult to behaviorally discriminate between endocrine-disruption and infodisruption. Animals may respond differently either because their hormones have been altered or because they cannot read the signals from another animal appropriately. An example of this is found in mating behavior. Testosterone and oestradiol levels which are important drivers in the mating behavior of many species are sensitive to endocrine-disrupting chemicals (Shenoy and Crowley, 2011). Male guppies with prolonged exposure to atrazine had reduced ornamentation, courtship displays, and aggression towards rival males (Shenoy, 2012). Info-disruption can cause similar results. Males of the striped lynx spider (Oxyopes salticus) are less likely to court in response to female cues that were deposited on pesticide residues of malathion, carbaryl, and bifenthrin (Hanna and Hanna, 2014). Due to the very short period of time that these spiders were on the treated substrate, we assume the change in behavior is not a result of hormonal shifts, but a disruption in the information they are attaining from the deposited female cues on pesticide treated substrates. Nevertheless, determining if and how animals respond behaviorally to chemicals is a critical first step to understanding their potential non-lethal effects. Shifts in behavioral traits would be indicative of the disruption of internal or external chemical communication.

The focus of this study will be on the herbicide chemical atrazine. Atrazine is the second most commonly used herbicide in the United States with between 33 and 36 million kilograms applied annually (Grube et al., 2011), with primary use in the spring for pre-emergent control of weeds in corn and sorghum fields. It is effective as an herbicide as it inhibits electron transport used in photosynthesis (Good, 1961) and also is known to be an endocrine-disruptor in animals. Atrazine is lipid soluble and can cross the blood brain barrier where it alters the function of gonadotropin-releasing hormone neurons in rats (Foradori et al., 2009). This has been suggested as a possible mechanism to explain observed dramatic effects in many species of vertebrates exposed to atrazine such as the demasculinization and feminization of male gonads (Hayes et al., 2011). Significant effects have also been seen in invertebrates. Male Drosophila melanogaster 
mating ability and the number of eggs his partner laid were negatively impacted from atrazine exposure of the male (Vogel et al., 2015). But atrazine may not have a similar effect on all animals. When Japanese quail, Coturnix coturnix japonica, were exposed, atrazine did not disrupt their endocrine system (Wilhelms et al., 2006) though this may just be a result of concentration used and length of exposure. Little is known of atrazine's impact on the behavior of arthropods although it is widely applied.

The dominant group of beneficial arthropods inhabiting agricultural systems are spiders (Marshall et al., 2002; Marshall and Rypstra, 1999; Young and Edwards, 1990). Spiders are valued for their role in minimizing crop damage from pest species by predation (Halaj and Wise, 2001; Schmitz et al., 2000), yet little is known of the potential info- or endocrine-disrupting effects atrazine may have on them. Exhaustive literature review found no publications on the impact of atrazine on the behavior of spiders, but there are data suggesting that many other pesticides impact their behavior and life history traits. Prolonged exposure to a commercial formulation of a glyphosate based herbicide has been linked to negative effects on prey consumption, web building, fecundity, fertility and developmental time of progeny in the araneid web spider, Alpaida veniliae (Benamú et al., 2010). It has also been shown to alter movement patterns and decrease survival (Evans et al., 2010), as well as disrupt chemotactile cues utilized in mate location in Pardosa milvina (Araneae, Lycosidae) (Griesinger et al., 2011). Effects aren't limited to glyphosate, exposure to malathion resulted in altered activity patterns and rhythms in several species of spiders (Tietjen and Cady, 2007).

Many pesticides have been linked to these sublethal effects that reduce spider populations in agricultural fields (Pekár, 2012). For example, a recent study in apple orchards showed that spider communities in areas of reduced pesticide usage had higher abundance, species richness, and diversity due to sublethal effects (Marliac et al., 2016). Community structure alone cannot sum up the impact of pesticides on these natural pest enemies. An investigation of eight different herbicides showed that they can weaken the natural pest control provided by Pardosa agrestis (Korenko et al., 2016). Similar results were also found in the web building spider Agalenatea redii, where pesticide application had a direct impact on predatory behavior and survival (Pasquet et al., 2016). While these studies covered several pesticides and showed sublethal effects impacting natural pest control, investigation still needs to be conducted on the impact of atrazine on spiders. 
The goal of this study is to understand the potential effects of atrazine on the behavior and reproduction of a wolf spider species that thrives in habitats where exposure is likely. Since nothing is known about the reactions of any spider to this herbicide, I will first determine if they detect and respond to atrazine by monitoring the activity of males and females on a surface treated with atrazine. In a second experiment I will determine if maturation, adult lifespan, mating behaviors, and reproductive success differ when spiders have been on treated substrate. In these experiments I hypothesize that Pardosa milvina will be able to detect atrazine and that it will increase activity level, while negatively impacting reproductive success and courtship behaviors as observed in these prior studies with other herbicides.

\section{Methods}

\section{Study Species:}

Pardosa milvina (Hentz 1844) is a native species of wolf spider (Araneae, Lycosidae) in agricultural fields across the eastern United States and is a major component of agricultural spider communities in southwest Ohio (Marshall et al., 2002). Behavior in this species has been well studied including movement and foraging (Wilder and Rypstra, 2004), antipredator response (M. H. Persons and Rypstra, 2001), habitat preference (Schmidt and Rypstra, 2010), and mating (Rypstra et al., 2003). Pardosa milvina is an epigeal species of spider which makes them sensitive to soil surface conditions (Marshall et al., 2006), including cues from both natural and anthropogenic sources (Evans et al., 2010; Griesinger et al., 2011; M. H. Persons and Rypstra, 2001; Wilder and Rypstra, 2004).

Pardosa milvina has been shown to be sensitive to natural chemotactile cues such as silk and feces (Rypstra et al., 2009; Wilder and Rypstra, 2004). For example, males and females respond to cues from a different wolf spider (Tigrosa helluo) that is a common predator by decreasing activity (M. H. Persons and Rypstra, 2001; Matthew H. Persons and Lynam, 2004). Cues deposited on silk that are excreted by a female are sufficient to elicit courtship from males, and also allow them to discriminate between previously mated females and virgins (Rypstra et al., 2003).

Males court by repeatedly raising their front pair of forelimbs in a vertical waving motion as well as sporadically shaking their body horizontally (Kaston, 1936; Montgomery, 1903). The 
male continuously courts with only a fraction of a second between individual leg raises, but this courtship can be intermittent in bouts (See Pardosa description in Montgomery, Thomas, 1903). A male may lose track of the female and then attempt to relocate her or just have a several second delay between displays. Courtship behavior can range in duration from seconds to minutes depending on how long it takes the female to accept the male.

Given how focused members of this species are on substrate-borne chemotactile cues, it is not surprising that they react to anthropogenic substances on substrates. Sensitivity of $P$. milvina to a commercial formulation of a glyphosate-based herbicide causes spiders to move faster but cover less distance and a short 30 minute exposure decreased survival (Evans et al., 2010). This same herbicide was also shown to disrupt chemical cues used by male $P$. milvina to locate females (Griesinger et al., 2011). The presence of a glyphosate-based herbicide also rendered them more susceptible to predation by disrupting chemical cues from predators (Rittman et al., 2013). This measurable sensitivity to glyphosate makes $P$. milvina a good model to consider possible impacts of the application of atrazine in agricultural fields.

\section{Spider Care and Maintenance:}

Spiders were collected from Miami University's Ecology Research Center 1.5 miles northeast of Oxford, Ohio, USA $\left(39^{\circ} 31^{\prime} \mathrm{N}, 84^{\circ} 43^{\prime} \mathrm{W}\right)$. After collection, all spiders were kept in cylindrical transparent plastic containers tapering from $5.0 \mathrm{~cm}$ in diameter at the base to $7.0 \mathrm{~cm}$ at the top. These containers are $6.0 \mathrm{~cm}$ tall and were covered with a plastic lid to prevent excess desiccation. Containers were filled to a depth of $2 \mathrm{~cm}$ with an even mixture of potting soil and peat moss which I kept moist by the weekly addition of approximately $3 \mathrm{ml}$ of water. The spiders were housed in an environmental chamber at $25^{\circ} \mathrm{C}$, with a relative humidity of approximately $18 \%$ and a 13:11 hour light:dark cycle. Once a week these spiders were taken out of the environmental chamber and fed two crickets (Gryllodes sigillatus), each approximately $3.2 \mathrm{~mm}$ in length.

\section{Herbicide Preparation:}

Atrazine 4L by WinField (St. Paul, Minnesota, USA), a commercial formulation of an atrazine-based herbicide, was used to replicate commercial agricultural conditions. As purchased, this formulation contains $41.12 \%$ of the active ingredient atrazine. The size of the 
arenas and the filter papers used to line the floor of arenas to deliver the atrazine differed between each experiment. Arenas in the activity experiment were larger in order to allow for adequate space to move around. I first determined the amount of liquid that each size of filter paper would absorb and worked back to calculate how much I needed to dilute the commercial product for coverage equivalent to $2.2 \mathrm{~kg}$ atrazine per hectare, which is within the application range of 1.7 and $2.8 \mathrm{~kg}$ per hectare used by local farmers in the Midwest (Jablonowski et al., 2008). All filter papers for both experiments were left to air dry isolated and uncovered in the laboratory at room temperature overnight before use in an experiment.

The activity experiment was run in cylindrical arenas that were $150 \mathrm{~mm}$ in diameter. I prepared a stock solution by adding $0.93 \mathrm{~g}$ of the commercial atrazine to $500 \mathrm{ml}$ of distilled water and then pipetted $5 \mathrm{ml}$ of this solution to filter paper cut to fit the bottom of the experimental container, equivalent to an application rate of $2.2 \mathrm{~kg}$ per hectare. Filter papers for the control group had an equivalent amount of distilled water applied to them following the same procedure. The reproductive studies were conducted on animals held in containers that were $7 \mathrm{~cm}$ in diameter. For this experiment, I added $1.05 \mathrm{~g}$ of the commercial atrazine to $500 \mathrm{ml}$ of distilled water and then applied $1 \mathrm{ml}$ of this solution to filter paper cut to fit the bottom of these containers, equivalent to an application of $2.2 \mathrm{~kg}$ per hectare. For this experiment, I added an intermediate dose of atrazine to get a better idea of the range of its potential effects. In order to obtain a half dose, $100 \mathrm{ml}$ of this solution was then added to $100 \mathrm{ml}$ of water before applying to the filter paper. The control paper was again treated with just an equivalent amount of water.

\section{Activity Experiment:}

The activity experiment aimed to determine whether spiders alter their activity levels in the presence of atrazine. Only mature adults were used in this study, with a total of 50 males and 50 females split evenly between exposure groups. Spiders that were about to undergo trials were provided two crickets, $3.2 \mathrm{~mm}$ in length, as food 72 hours prior to the date of trial to try to control for hunger levels. Then, to document the size and condition of the spiders, abdomen width and carapace width were recorded using a Wild MMS235 micrometer (Heerbrugg, Switzerland) attached to a dissection microscope 24 hours prior to trial. This micrometer is accurate to $0.01 \mathrm{~mm}$. 
Two $15 \mathrm{~cm}$ diameter arenas were created out of plexiglass and $20 \mathrm{~cm}$ tall acetate sheets. One container was designated for atrazine trials, while the other was designated for control trials. Corresponding to the exposure group (control or atrazine), filter paper was placed on the floor of the arena. These arenas were then set inside of an environmental chamber at $25^{\circ} \mathrm{C}$ with a relative humidity of approximately $18 \%$. Next I introduced a spider to the center of the arena in an inverted glass vial and allowed a 1 minute acclimation period (as in M. H. Persons \& Rypstra, 2001). Then, I recorded each individual as they explored the arena for 15 minutes using a mounted Panasonic PalmcorderTM PV-DV52D (Kadoma, Osaka, Japan). Spiders were used for only one trial. After each trial, the filter paper was disposed and arenas were wiped down with $70 \%$ EtOH. I used Noldus EthoVision ${ }^{\mathrm{TM}}$ XT (Wageningen, The Netherlands) software to summarize the activity of the spiders including: distance traveled $(\mathrm{cm})$, velocity $(\mathrm{cm} / \mathrm{s})$, angular velocity (deg/s), meander (deg/cm), and frequency (number of unique times in state during trial) and time (s) spent immobile, mobile, and highly mobile. Thresholds of mobility were set at 0 (immobile), 20\% (mobile), and 60\% (highly mobile), which represents changes in body position between frames (10 frames per second).

\section{Statistical Analysis:}

Size and body condition of the spiders were found to be normally distributed and met assumptions necessary for parametric testing. Measurements were compared between the two exposure groups by sex with individual t-tests, carapace width and abdomen width were compared across groups for size differences while the ratio of the two (carapace / abdomen) was used as a metric of body condition (see Anderson, 1974). Activity metrics were combined using Principal Components Analysis. I entered all activity metrics into PCA and retained those PCs with eigen values greater than one. I tested the hypothesis that atrazine affected activity by comparing the retained PCs using two-way ANOVAs with exposure and sex as factors. The interactions were retained only if significant. All statistical analyses were performed in SAS JMP Pro 11.2.0.

\section{Reproduction Experiment:}

Immature spiders were moved upon completing their penultimate molt into $7 \mathrm{~cm}$ diameter clear, cylindrical containers which had the floor lined with filter paper corresponding to 
the exposure group (control, half dose, full dose). At time of introduction, a small cap ( $1 \mathrm{~cm}$ diameter, $1 \mathrm{~cm}$ height) with a moistened cotton ball placed in it was also inserted in the center to provide the spider access to water. Feeding was increased to two $3.2 \mathrm{~mm}$ crickets twice a week, with two days in between, to remove any impact hunger might have during courtship.

Spider containers were checked daily for molts and deaths. When a molt was found, the number of days it took to complete the final molt was recorded. This ranged from 1 to 117 days. After completing the molt, the spider was placed in queue for mating. When a member of the same exposure group but opposite sex completed the ultimate molt, a week was given to recover. I then gave the two spiders the opportunity to mate 24 hours after feeding. A total of 237 spiders were used in this study. The full dose group consisted of 45 males and 50 females, the half dose group had 38 males and 45 females, and the control group consisted of 30 males and 29 females. With these spiders I achieved a minimum sample size of 20 mating attempts per each individual exposure group. Not all spiders survived long enough or completed the ultimate molt, which is why the total number of spiders used is not representative of just the number of mating attempts.

Spiders were mated in containers with a filter paper substrate which was treated corresponding to their home containers. The female was first placed into a $15 \mathrm{~cm}$ diameter plastic arena ( $7.5 \mathrm{~cm}$ high) inside an isolated booth in an environmental chamber. I allowed her to acclimate and deposit cues for 15 mins, and then sequestered her underneath a glass vial. Next I introduced the male into the arena sequestered underneath a clear glass vial. He was allowed to acclimate for 3 minutes underneath the vial, and then I removed the vials and allowed them to interact for 45 minutes or until copulation completed. All trials were recorded using a mounted Panasonic Palmcorder ${ }^{\text {TM }}$ PV-DV52D (Kadoma, Osaka, Japan). I tallied the number of distinct male leg raises and body shakes during the final bout of courtship prior to successful copulation when male display is at its peak, or during the most intense display by the male if no copulation occurred. The duration of this most intense bout of courtship, latency to begin mating, and copulation duration were also recorded.

After trials, spiders were replaced into their respective containers and were checked daily until death. Regular feeding of two crickets once a week continued and I recorded if and when an egg sac appeared with the females. Once an egg sac developed, I removed it and recorded the sac's mass as well as the number of eggs inside. Adult lifespan of all spiders was also recorded to see if atrazine exposure affected survival. 


\section{Statistical Analysis:}

I tested the hypothesis that atrazine affected the spider's progression through maturity and reproductive success by comparing the experimental and control groups for the duration of the penultimate stage by sex, time to copulation, time from mating to the production of an egg sac, and the adult lifespan by sex using a right censored proportional hazards model. If a significant effect was found, pairwise comparisons among all the three exposure groups were made using proportional hazards models with an adjusted critical $p$ value of 0.017 in order to account for the multiple testing of the same data (Bonferroni correction to minimize type 1 errors as in Pearce-Higgins, Eglington, Martay, \& Chamberlain, 2015). The number of spiders that died while completing the final molt, number of spiders that produced an egg sac, as well as a second egg sac, and mating success were compared among exposure groups using a Fisher's Exact Test. The number of leg raises and body shakes per minute, duration of the most intense bout of courtship, copulation duration, and number of eggs were compared using a one-way ANOVA to look for potential differences between the exposure groups. Significant differences from the ANOVA were then analyzed using a Tukey-Kramer HSD post hoc test for pairwise comparisons. Egg sac mass was compared using a two-way ANOVA with exposure and number of eggs in the sac as factors. Tukey-Kramer HSD post hoc analysis was performed for pairwise comparisons. Finally, logistic regression was used to determine if the length of atrazine exposure before mating impacted the probability that the female would produce an egg sac, and if the length of the most intense bout of courtship or rate of leg raises or body shakes could predict successful copulation. All metrics used in parametric analyses were observed to meet the necessary assumptions of parametric testing.

\section{Results}

\section{Effect on activity:}

While females were larger than males, spiders were similar in size and overall body condition among exposure groups (Table 1), allowing for comparisons to be made on activity patterns. Two principal components emerged with eigen vectors greater than one. The highest activity loadings for PC1 were distance and duration of movement as well as mean velocity 
(Table 2). Larger PC1 values represented spiders covering larger distances, spending less time stationary, and having a higher mean velocity. The highest loadings for PC2 were frequency and durations of mobility periods (Table 2). Larger PC2 values represented spiders spending less time mobile but spending more time at high velocity. Males were found to exhibit higher values of PC1, but lower values of PC2 when compared to females (Fig. 1, Fig. 2, Table 3). Presence of atrazine did not impact PC1, but spiders in arenas treated with the herbicide exhibited a lower value of PC2 (Fig. 1B, Fig. 2, Table 3).

\section{Effect on maturation and survival:}

Maturation and survival of $P$. milvina were negatively impacted by the presence of atrazine. Females took longer to complete the final molt than males but exposure to the herbicide significantly delayed completion of the ultimate molt for males (Fig. 3, Table 4). Males were also much more likely to have a bad molt than females, and increasing dosage of atrazine increased proportion of bad molt attempts by both sexes (Table 5, Table 6). These faulty molts resulted in a spider losing an appendage, having a curled leg, or dying. Finally, exposure to atrazine decreased adult lifespan for both sexes (Fig. 4, Table 4).

\section{Effect on courtship and reproduction:}

Courtship was unaffected by atrazine exposure as the rate of leg raises and body shakes did not differ between groups (Table 7). The rate of leg raises also was not indicative of successful copulation, but the higher the rate of body shakes a male performed, the more successful he was in mating (Table 5). The duration of the most intense bout of courtship was not found to differ between groups (Table 7), nor was it a good predictor of successful copulation (Table 5). The proportion of trials that led to successful copulations was not affected by exposure to atrazine (Table 8). Finally, neither the latency to copulation (Table 4), nor the duration of copulation (Table 7) were affected by exposure.

Reproductive success appears to be impacted in complex ways by the presence of atrazine. There was no observed difference in the proportion of mated females that successfully produced an initial egg sac (Table 8), nor in the latency of producing that egg sac after mating (Table 4). Though, for the full dose group, the longer a female was exposed prior to mating the less likely she was to produce that initial egg sac (Fig 5). This phenomenon was not observed in 
the other exposure groups (Table 9). After producing an initial egg sac, females exposed to the full dose of atrazine were much more likely to produce a second egg sac after the single mating (Table 8). Intriguingly, I also found that the egg sacs produced by the half dose group were larger in mass than those produced by females in the control or full dose group (Fig. 6, Table 10), while there was no difference found in the average number of eggs contained in each sac (Table 7).

\section{Discussion}

This study provides a first insight on the impact of atrazine on an agrobiont spider that thrives in habitats where atrazine is routinely applied. Unlike previous studies on numerous different taxa including amphibians and fish, I did not find evidence of info-disruption in these spiders based on the interactions between males and females during courtship and mating. Intriguingly though, atrazine was found to impact various maturation and reproductive traits of these spiders, suggesting that they are at risk of endocrine-disruption from exposure. I also found shifts in activity and adult lifespan due to exposure. These various impacts may be placing selective pressures upon P. milvina in these agricultural fields, which could result in changes in the food webs of these agricultural ecosystems. The results of this study further demonstrate the need to investigate anthropogenic chemical inputs beyond lethality.

\section{Activity:}

Combining activity metrics into principal components allowed me to observe differences in mobility that would not have been noticed by the comparison of individual metrics across groups. This study found that PC2 was reduced by the presence of atrazine in comparison to controls. This result demonstrates that $P$. milvina alter their behavior in response to exposure. There was no interaction effect of sex and exposure found in PC2 which showed that females and males responded similarly to atrazine. While males scored lower in general in PC2 than females, the presence of atrazine resulted in female scores similar to control males. This jerky pattern of movement is similar to previous results showing red drum larvae becoming hyperactive and swimming in more convoluted paths (Alvarez and Fuiman, 2005). It may result in higher risk of predation as P. milvina have be shown to become more immobile and slow 
down as predator response behavior when exposed to chemical cues from predators (Barnes et al., 2002). Further support for this idea is shown in a recent study on another herbicide, glyphosate, which caused a larger wolf spider to target and capture $P$. milvina more rapidly (Rittman et al., 2013).

I also found that the sex of the spider explained a large portion of variation in activity. Males on average moved faster, further, and in more jerky patterns than females. This is consistent with a previous study of wandering spiders (Schmitt et al., 1990), and may be a result of male mating strategy. Males are often the sex that actively seek out mating partners, responding to chemical cues emitted by females (Griesinger et al., 2011). Females on the other hand, seem to rely on visual stimuli provided by a male during courtship (Rypstra et al., 2003). Interestingly, a prior study on these spiders uncovered no differences in the activity of female and male spiders (Walker and Rypstra, 2003). The composite metrics generated by PCA provides a more accurate picture of subtle differences in activity that may occur in a range of variables, none of which are different when considered singly.

\section{Courtship and Reproduction:}

The occurrence of courtship and the rate at which males courted females, as measured by body shakes or leg raises, was not affected by the presence of atrazine. The lack of an impact from an herbicide on courtship differs from the impact of various insecticides on the spider Oxyopes salticus which showed that courtship behaviors by males were less likely to occur on substrates treated with the insecticides (Hanna and Hanna, 2014). Perhaps differences between herbicides and insecticides may lead to differing side effects. Atrazine could therefore be impacting these agrobiont species in unique ways instead of falling under a larger umbrella of pesticides. Also, the study by Hanna and Hanna (2014) only used chemical cues from a female to elicit the courtship response, as the female was removed from sight of the male. Thus, they do not have complete information as to how the pesticide impacts mating success. A study on visual and chemical cues in P. milvina found that these were in large part redundant signals but combined could provide increased motivation (Rypstra et al., 2009), which supports this idea.

To address the issue of info-disruption more explicitly in the future, virgin females and previously mated females can be used in mating trials on substrates treated with atrazine, rather than just virgin females which this study utilized. Rypstra et al. (2003) showed that male $P$. 
milvina exhibit a higher rate of courtship behavior to virgin females than those that have mated before. This would provide for an expected difference in courtship rates based on chemical cues, giving insight into the info-disruption that might be occurring from atrazine.

Females that had successfully mated were equally likely to produce an egg sac regardless of exposure, but there was a significant impact from the time that a female was exposed to the full dose on egg sac production. While atrazine did not appear to cause an immediate effect on the proportion of mated females to produce an egg sac, the longer a female was exposed to the full dose during her penultimate instar, the less likely she was to produce an egg sac. This trend was not seen in at lower concentrations, providing support for the idea that atrazine negatively impacts female reproductive success.

Intriguingly, females on the full dose of atrazine were more likely to produce a second egg sac, and egg sacs produced by spiders in the half dose group were larger in mass than other groups. Atrazine may in this regard be mimicking a hormone or reproductive regulator, resulting in increased egg sac production or mass. There may also be a shift in female reproductive strategy. Males in this study were very negatively impacted in regards to maturation time and molting success by exposure to atrazine. Females in response may utilize sperm from a single mating more rapidly to produce a second sac or produce a larger sac, instead of holding off to see if a better mate can be found.

Another recent study has shown that individual egg mass in a species of spider is affected by the amount of food available to the mother (Johnson et al., 2014). Female spiders that consumed more prey items produced eggs of a larger mass than those that fed less. These eggs then developed through the larval stage more rapidly than those eggs of less mass. In my experiment, females in the half dose group may be providing extra benefit to their offspring by increasing individual egg mass to the detriment of their own health, which is evidenced by the significantly decreased adult lifespan. This would allow for rapid early development, which could be critical for surviving the pre-emergent application of atrazine that occurs in the spring when many egg sacs are produced. The full dose group may be overwhelmed and unable to spare the resources necessary to yolk up the eggs, but instead attempt to maintain their own health.

\section{Maturation and Survival:}


Exposure to atrazine significantly delayed the completion of the ultimate molt in male spiders, leaving them sexually immature for longer. Also, when spiders exposed to atrazine finally attempted to molt, there was increased risk of a faulty molt which at times resulted in death midway through the process. The molting process of arthropods is heavily dependent on endocrine regulation, such as through the hormone ecdysone, which makes it especially vulnerable to endocrine disruption (Song et al., 2017). As males were found to be the most impacted, this could lead to a limited pool of reproductively active males resulting in a femalebiased sex ratio. Since the females of this species are the choosier sex when evaluating a mate, this may result in a decrease in selection pressure on males or even introduce female competition in the system in extreme cases (Fritzsche et al., 2016). Not only did exposure to atrazine cause $P$. milvina to stay immature for longer and increase mortality during maturation, but even after completing the ultimate molt adult lifespans decreased as the dose of atrazine increased.

In this study, I sacrificed all egg sacs that a female produced to count the number of eggs it contained. There is the potential of effects carrying-over to offspring. A study on organophosphate-based pesticides found that unexposed offspring from females that were exposed to the pesticide took longer to mature and were also smaller than control spiders (Peng et al. 2010). If similar results were found from exposure to atrazine, carry-over effects could result in an even larger delay in maturation in this species which may in turn place even larger selective pressure on this valuable predatory arthropod.

\section{Conclusion:}

These results suggest that exposure to a commercially available atrazine-based herbicide influences the activity patterns and life history traits of Pardosa milvina in complex ways which far extend beyond lethality. These changes may then in turn have an impact on populations of $P$. milvina, leading to alterations in the food web of these agroecosystems. In conclusion, we now know that the dramatic impacts of atrazine on exposed wildlife are not limited to species of vertebrates that encounter it through agricultural runoff, but can also occur in invertebrates that call these agricultural fields home. 


\section{Literature Cited}

Alvarez, M. D. C., and Fuiman, L. A. (2005). Environmental levels of atrazine and its degradation products impair survival skills and growth of red drum larvae. Aquatic Toxicology, 74(3), 229-241.

Anderson, J. F. (1974). Responses to starvation in the spiders Lycosa Lenta Hentz and Filistata Hibernalis ( Hentz ). Ecological Society of America, 55(3), 576-585.

Barnes, M. C., Persons, M. H., and Rypstra, A. L. (2002). The effect of predator chemical cue age on antipredator behavior in the wolf spider Pardosa milvina (Araneae: Lycosidae). Journal of Insect Behavior, 15(2), 269-281.

Benamú, M. A., Schneider, M. I., and Sánchez, N. E. (2010). Effects of the herbicide glyphosate on biological attributes of Alpaida veniliae (Araneae, Araneidae), in laboratory. Chemosphere, 78(7), 871-876.

Castorani, M. C. N., and Hovel, K. A. (2016). Native predator chemical cues induce antipredation behaviors in an invasive marine bivalve. Biological Invasions, 18(1), 169-181.

Cinková, I., and Policht, R. (2015). Discrimination of familiarity and sex from chemical cues in the dung by wild southern white rhinoceros. Animal Cognition, 18(1), 385-392.

Ehrsam, M., Knutie, S. A., and Rohr, J. R. (2016). The herbicide atrazine induces hyperactivity and compromises tadpole detection of predator chemical cues. Environmental Toxicology and Chemistry, 35(9), 2239-2244.

Evans, S. C., Shaw, E. M., and Rypstra, A. L. (2010). Exposure to a glyphosate-based herbicide affects agrobiont predatory arthropod behaviour and long-term survival.

Foradori, C. D., Hinds, L. R., Hanneman, W. H., and Handa, R. J. (2009). Effects of atrazine and its withdrawal on gonadotropin-releasing hormone neuroendocrine function in the adult female Wistar rat. Biology of Reproduction, 81(6), 1099-1105.

Fritzsche, K., Booksmythe, I., and Arnqvist, G. (2016). Sex ratio bias leads to the evolution of sex role reversal in honey locust beetles. Current Biology, 26(18), 2522-2526.

Goetz, A. K., Ren, H., Schmid, J. E., Blystone, C. R., Thillainadarajah, I., Best, D. S., ... Dix, D. J. (2007). Disruption of testosterone homeostasis as a mode of action for the reproductive toxicity of triazole fungicides in the male rat. Toxicological Sciences, 95(1), 227-239.

Good, N. E. (1961). Inhibitors of the Hill reaction. Plant Physiology, 36(6), 788-803. 
Griesinger, L. M., Evans, S. C., and Rypstra, A. L. (2011). Effects of a glyphosate-based herbicide on mate location in a wolf spider that inhabits agroecosystems. Chemosphere, 84(10), 1461-1466.

Grube, A., Donaldson, D., Kiely, T., and Wu, L. (2011). Pesticides industry sales and usage: 2006 and 2007 market estimates. U.S. Environmental Protection Agency, 1-41.

Halaj, J., and Wise, D. H. (2001). Terrestrial trophic cascades: how much do they trickle? The American Naturalist, 157(3), 262-281.

Hanazato, T. (1999). Antrhopogenic chemicals (insecticides) disturb natural organic chemical communication in the plankton community. Envir. Pollut., 105, 137-142.

Hanna, C., and Hanna, C. (2014). Sublethal pesticide exposure disrupts courtship in the striped lynx spider, Oxyopes salticus (Araneae: Oxyopidae). Journal of Applied Entomology, $138(1-2), 141-148$.

Hayes, T. B., Anderson, L. L., Beasley, V. R., De Solla, S. R., Iguchi, T., Ingraham, H., ... Willingham, E. (2011). Demasculinization and feminization of male gonads by atrazine: consistent effects across vertebrate classes. Journal of Steroid Biochemistry and Molecular Biology, 127(1-2), 64-73.

Holding, M. L., Kern, E. H., Denton, R. D., and Gibbs, H. L. (2016). Fixed prey cue preferences among Dusky Pigmy Rattlesnakes (Sistrurus miliarius barbouri) raised on different longterm diets. Evolutionary Ecology, 30(1), 1-7.

Jablonowski, N. D., Koeppchen, S., Hofmann, D., Schaeffer, A., and Burauel, P. (2008). Spatial distribution and characterization of long-term aged 14C-labeled atrazine residues in soil. Journal of Agricultural and Food Chemistry, 56(20), 9548-9554.

Johnson, J. C., Miles, L. S., Trubl, P. J., and Hagenmaier, A. (2014). Maternal effects on egg investment and offspring performance in black widow spiders. Animal Behaviour, 91, 6773.

Kaston, B. J. (1936). The senses involved in the courtship of some vagabond spiders. Entomologica Americana, 16, 97-166.

Korenko, S., Niedobová, J., Kolářová, M., Hamouzová, K., Kysilková, K., and Michalko, R. (2016). The effect of eight common herbicides on the predatory activity of the agrobiont spider Pardosa agrestis. BioControl, 61(5), 507-517.

Lal, B., Sarang, M. K., and Kumar, P. (2013). Malathion exposure induces the endocrine 
disruption and growth retardation in the catfish, Clarias batrachus (Linn.). General and Comparative Endocrinology, 181(1), 139-145.

Lane, S. M., Solino, J. H., Mitchell, C., Blount, J. D., Okada, K., Hunt, J., and House, C. M. (2015). Rival male chemical cues evoke changes in male pre- and post-copulatory investment in a flour beetle. Behavioral Ecology, 26(4), 1021-1029.

Li, Z., Li, B., Hu, Z., Michaud, J. P., Dong, J., Zhang, Q., and Liu, X. (2015). The ectoparasitoid Scleroderma guani (Hymenoptera: Bethylidae) uses innate and learned chemical cues to locate its host, larvae of the Pine Sawyer Monochamus alternatus (Coleoptera: Cerambycidae). Florida Entomologist, 98(4), 1182-1187.

Lürling, M., and Scheffer, M. (2007). Info-disruption: pollution and the transfer of chemical information between organisms. Trends in Ecology and Evolution, 22(7), 374-379.

Marliac, G., Mazzia, C., Pasquet, A., Cornic, J. F., Hedde, M., and Capowiez, Y. (2016). Management diversity within organic production influences epigeal spider communities in apple orchards. Agriculture, Ecosystems and Environment, 216, 73-81.

Marshall, S. D., Pavuk, D. M., and Rypstra, A. L. (2002). A comparative study of phenology and daily activity patterns in the wolf spiders Pardosa milvina and Hogna helluo in soybean agroecosystems in southwestern Ohio (Araneae, Lycosidae). Journal of Arachnology, 30, 503-510.

Marshall, S. D., and Rypstra, A. L. (1999). Spider competition in structurally simple ecosystems. The Journal of Arachnology, 27, 343-350.

Marshall, S. D., Walker, S. E., and Rypstra, A. L. (2006). Two ecologically-divergent generalist predators have different responses to landscape fragmentation. Oikos, 114(2), 241-248.

Meyer-Lucht, Y., Poschadel, J., and Plath, M. (2006). Response to chemical cues from conspecifics reflects male mating preference for large females and avoidance of large competitors in the European pond turtle, Emys orbicularis. Behaviour, 143, 569-587.

Montgomery, T. H. (1903). Studies on the habits of spiders, particularly those of the mating period. Academy of Natural Sciences, 55(1903), 59-149.

Nussey, S., and Whitehead, S. A. (2001). Endocrinology: An Integrated Approach (First). Oxford: CRC Press.

Pasquet, A., Tupinier, N., Mazzia, C., and Capowiez, Y. (2016). Exposure to spinosad affects orb-web spider (Agalenatea redii) survival, web construction and prey capture under 
laboratory conditions. Journal of Pest Science, 89(2), 507-515.

Pearce-Higgins, J. W., Eglington, S. M., Martay, B., and Chamberlain, D. E. (2015). Drivers of climate change impacts on bird communities. Journal of Animal Ecology, 84(4), 943-954.

Pekár, S. (2012). Spiders (Araneae) in the pesticide world: An ecotoxicological review. Pest Management Science, 68(11), 1438-1446.

Persons, M. H., and Lynam, E. C. (2004). Pardosa milvina (Araneae, Lycosidae) spiderling movement in the presence of conspecific and heterospecific silk and excreta. Journal of Arachnology, 32(2), 341-344.

Persons, M. H., and Rypstra, A. L. (2001). Wolf spiders show graded antipredator behavior in the presence of chemical cues from different sized predators. Journal of Chemical Ecology, 27(12), 2493-2504.

Rittman, S., Wrinn, K. M., Evans, S. C., Webb, A. W., and Rypstra, A. L. (2013). Glyphosatebased herbicide has contrasting effects on prey capture by two co-occurring wolf spider species. Journal of Chemical Ecology, 39(10), 1247-1253.

Rypstra, A. L., Schlosser, A. M., Sutton, P. L., and Persons, M. H. (2009). Multimodal signalling: the relative importance of chemical and visual cues from females to the behaviour of male wolf spiders (Lycosidae). Animal Behaviour, 77(4), 937-947.

Rypstra, A. L., Wieg, C., Walker, S. E., and Persons, M. H. (2003). Mutual mate assessment in wolf spiders: differences in the cues used by males and females. Ethology, 109(4), 315-325.

Schmidt, J. M., and Rypstra, A. L. (2010). Opportunistic predator prefers habitat complexity that exposes prey while reducing cannibalism and intraguild encounters. Oecologia, 164(4), 899-910.

Schmitt, A., Schuster, M., and Barth, F. G. (1990). Daily locomotor activity patterns in three species of Cupiennius ( Araneae, Ctenidae): the males are the wandering spiders. The Journal of Arachnology, 18(3), 249-255.

Schmitz, O. J., Hambäck, P. a., and Beckerman, A. P. (2000). Trophic cascades in terrestrial systems: a review of the effects of carnivore removals on plants. The American Naturalist, 155(2), 141-153.

Schug, T. T., Janesick, A., Blumberg, B., and Heindel, J. J. (2011). Endocrine disrupting chemicals and disease susceptibility. Journal of Steroid Biochemistry and Molecular Biology, 127(3-5), 204-215. 
Secondi, J., Hinot, E., Djalout, Z., Sourice, S., and Jadas-Hécart, A. (2009). Realistic nitrate concentration alters the expression of sexual traits and olfactory male attractiveness in newts. Functional Ecology, 23(4), 800-808.

Shenoy, K. (2012). Environmentally realistic exposure to the herbicide atrazine alters some sexually selected traits in male guppies. PLoS ONE, 7(2).

Shenoy, K., and Crowley, P. H. (2011). Endocrine disruption of male mating signals: ecological and evolutionary implications. Functional Ecology, 25(3), 433-448.

Sherba, M., Dunham, D. W., and Harvey, H. H. (2000). Sublethal copper toxicity and food response in the freshwater crayfish Cambarus bartonii (Cambaridae, Decapoda, Crustacea). Ecotoxicology and Environmental Safety, 46(3), 329-333.

Song, Y., Villeneuve, D. L., Toyota, K., Iguchi, T., and Tollefsen, K. E. (2017). Ecdysone receptor agonism leading to lethal molting disruption in arthropods: review and adverse outcome pathway development. Environmental Science and Technology, 51(8), 4142-4157.

Taxvig, C., Hass, U., Axelstad, M., Dalgaard, M., Boberg, J., Andeasen, H. R., and Vinggaard, A. M. (2007). Endocrine-disrupting activities in vivo of the fungicides tebuconazole and epoxiconazole. Toxicological Sciences, 100(2), 464-473.

Tietjen, W. J., and Cady, A. B. (2007). Sublethal exposure to a neurotoxic pesticide affects activity rhythms and patterns of four spider species. Journal of Arachnology, 35(2), 396406.

Vogel, A., Jocque, H., Sirot, L. K., and Fiumera, A. C. (2015). Effects of atrazine exposure on male reproductive performance in Drosophila melanogaster. Journal of Insect Physiology, $72,14-21$.

Walker, S. E., and Rypstra, A. L. (2003). Sexual dimorphism and the differential mortality model: is behaviour related to survival? Biological Journal of the Linnean Society, 78(1), 97-103.

Wilder, S. M., and Rypstra, A. L. (2004). Chemical cues from an introduced predator (Mantodea, Mantidae) reduce the movement and foraging of a native wolf spider (Araneae, Lycosidae) in the laboratory. Environmental Entomology, 33(4), 1032-1036.

Wilgers, D. J., Wickwire, D., and Hebets, E. a. (2014). Detection of predator cues alters mating tactics in male wolf spiders. Behaviour, 151(5), 573-590.

Wilhelms, K. W., Cutler, S. A., Proudman, J. A., Carsia, R. V., Anderson, L. L., and Scanes, C. 
G. (2006). Lack of effects of atrazine on estrogen-responsive organs and circulating hormone concentrations in sexually immature female Japanese quail (Coturnix coturnix japonica). Chemosphere, 65(4), 674-681.

Wyatt, T. D. (2014). Pheromones and Animal Behavior Chemical Signals and Signatures (Second). Cambridge: Cambridge University Press.

Young, O. P., and Edwards, G. B. (1990). Spiders in United States field crops and their potential effect on crop pests. Journal of Arachnology, 18(1), 1-27.

Yu, L., Chen, M., Liu, Y., Gui, W., and Zhu, G. (2013). Thyroid endocrine disruption in zebrafish larvae following exposure to hexaconazole and tebuconazole. Aquatic Toxicology, $138-139,35-42$. 


\section{Tables and Figures}

Table 1. Mean $( \pm$ SEM) carapace and abdomen widths of male and female Pardosa milvina comparing control and atrazine groups.

\begin{tabular}{lclll}
\hline Metric & n & Control & Atrazine & p \\
\hline Female & 25 & & & \\
Carapace Width $(\mathrm{mm})$ & & $2.38 \pm 0.05$ & $2.38 \pm 0.04$ & 0.91 \\
Abdomen Width $(\mathrm{mm})$ & $2.66 \pm 0.07$ & $2.73 \pm 0.08$ & 0.52 \\
Carapace/Abdomen & & $0.90 \pm 0.02$ & $0.89 \pm 0.03$ & 0.74 \\
Male & 25 & & & \\
Carapace Width $(\mathrm{mm})$ & & $2.27 \pm 0.06$ & $2.20 \pm 0.05$ & 0.37 \\
Abdomen Width $(\mathrm{mm})$ & $2.00 \pm 0.07$ & $1.95 \pm 0.05$ & 0.59 \\
Carapace/Abdomen & $1.16 \pm 0.04$ & $1.14 \pm 0.03$ & 0.75 \\
\hline
\end{tabular}


Table 2. First two principal components loadings of activities for Pardosa milvina treated with atrazine and controls. Percent of variation explained by each component are shown. The four most extreme values of loadings for the various vectors in each principal component are highlighted. These represent the most important activities for that principal component.

\begin{tabular}{lrr}
\hline \multicolumn{1}{c}{ Vector } & PC1 (45.0\%) & PC2 (10.6\%) \\
\hline Mean Angular velocity (degrees/second) & -0.22526 & 0.1282 \\
Total Distance moved (cm) & 0.23358 & 0.20871 \\
Duration Immobile (seconds) & -0.24787 & 0.11156 \\
Frequency Immobile & 0.19813 & -0.30018 \\
Duration Mobile (seconds) & 0.19435 & -0.32122 \\
Frequency Mobile & 0.22509 & -0.24676 \\
Duration Highly Mobile (seconds) & 0.21119 & 0.28168 \\
Frequency Highly Mobile & 0.22321 & 0.05808 \\
Mean Turn angle (degrees) & -0.22526 & 0.1282 \\
Mean Velocity (cm/second) & 0.23951 & 0.19662 \\
\hline
\end{tabular}


Table 3. Results from two-way ANOVAs on principal component 1 and principal component 2 comparing behaviors of Pardosa milvina treated with atrazine against control animals. Model and parameter output included.

\begin{tabular}{lllc}
\hline \multicolumn{1}{c}{ Model Features } & df & Test Statistic & p \\
\hline Sex and Exposure Predicting PC1 & & & \\
Model & 2,98 & $\mathrm{~F}=2.17$ & 0.119 \\
$\quad$ Sex & $\mathrm{t}=-2.08$ & 0.040 \\
$\quad$ Exposure & $\mathrm{t}=0.15$ & 0.883 \\
Sex and Exposure Predicting PC2 & & \\
Model & 2,98 & $\mathrm{~F}=10.58$ & $<0.001$ \\
$\quad$ Sex & $\mathrm{t}=4.02$ & $<0.001$ \\
$\quad$ Exposure & $\mathrm{t}=2.19$ & 0.031 \\
\hline
\end{tabular}


Table 4. Results of proportional hazard models on the timing of the ultimate molt, time to copulation, time to produce an egg sac, and adult lifespan for Pardosa milvina comparing control and atrazine-exposed spiders. Model and parameter output included.

\begin{tabular}{|c|c|c|c|c|}
\hline Model & $\mathbf{n}$ & df & $\mathbf{X}^{2}$ & $\mathbf{p}$ \\
\hline \multicolumn{5}{|l|}{ Days to Complete Ultimate Molt } \\
\hline Model & 108 & 4 & 29.49 & $<0.001$ \\
\hline Sex & & 1 & 4.45 & 0.035 \\
\hline Exposure & & 2 & 14.45 & $<0.001$ \\
\hline Days in Penult Molt Before Experiment & & 1 & 17.88 & $<0.001$ \\
\hline \multicolumn{5}{|l|}{ Time to Copulation } \\
\hline Model & 63 & 2 & 0.29 & 0.86 \\
\hline Exposure & & 2 & 0.29 & 0.86 \\
\hline \multicolumn{5}{|l|}{ Time to Produce Egg Sac } \\
\hline Model & 20 & 2 & 0.23 & 0.89 \\
\hline Exposure & & 2 & 0.23 & 0.89 \\
\hline \multicolumn{5}{|l|}{ Adult Lifespan } \\
\hline Model & 179 & 4 & 107.55 & $<0.001$ \\
\hline Sex & & 1 & 4.99 & 0.026 \\
\hline Exposure & & 2 & 13.03 & 0.002 \\
\hline Days Exposed & & 1 & 98.14 & $<0.001$ \\
\hline
\end{tabular}


Table 5. Results of logistic regressions on the number of faulty molts and copulation success by Pardosa milvina exposed to atrazine compared to control animals.

\begin{tabular}{lrrrr}
\hline \multicolumn{1}{c}{ Model } & n & df & $\mathbf{X}^{\mathbf{2}}$ & \multicolumn{1}{c}{$\mathbf{p}$} \\
\hline Faulty Molt & & & & \\
Model & 179 & 4 & 21.45 & $<0.001$ \\
Sex & & 1 & 12.84 & $<0.001$ \\
Treatment & 2 & 9.36 & 0.009 \\
Days in Treatment & & 1 & 0.30 & 0.586 \\
Copulation Success & 56 & 5 & 30.11 & $<0.001$ \\
Model & & 2 & 0.38 & 0.83 \\
Exposure & & 1 & 2.15 & 0.14 \\
Duration of Most Intense Bout of Courtship & & & & \\
Rate of Leg Raises & & 1 & 0.89 & 0.35 \\
Rate of Body Shakes & & 1 & 15.22 & $<0.001$ \\
\hline
\end{tabular}


Table 6. Number and percentage of Pardosa milvina categorized by sex and exposure to atrazine that was found to have undergone a faulty molt while attempting to complete the ultimate molt.

\begin{tabular}{llll}
\hline Sex & Control & Half Dose & Full Dose \\
\hline Female & $0 / 24(0 \%)$ & $2 / 28(7.1 \%)$ & $5 / 33(15.2 \%)$ \\
Male & $4 / 27(14.8 \%)$ & $8 / 32(25 \%)$ & $14 / 35(40.0 \%)$ \\
\hline
\end{tabular}


Table 7. Results from ANOVAs on various reproductive variables for Pardosa milvina treated with atrazine. Values are presented as the mean \pm standard error followed by number of individuals tested in parentheses. Bonferroni correction was applied to the critical significance level for courtship statistics which would provide a $p$ value $<0.01$.

\begin{tabular}{|c|c|c|c|c|c|c|}
\hline Metric & Control & Half Dose & Full Dose & df & $\mathbf{F}$ & $\mathbf{p}$ \\
\hline $\begin{array}{l}\text { Rate of Leg Raises } \\
\text { (leg raises per minute) }\end{array}$ & $55.5 \pm 5.3(22)$ & $53.5 \pm 5.5(20)$ & $54.1 \pm 5.4(21)$ & 2,62 & 0.039 & 0.962 \\
\hline $\begin{array}{l}\text { Rate of Body Shakes } \\
\text { (body shakes per minute) }\end{array}$ & $23.7 \pm 2.7(22)$ & $23.4 \pm 2.9(20)$ & $26.2 \pm 2.8(21)$ & 2,62 & 0.292 & 0.748 \\
\hline $\begin{array}{l}\text { Duration of Most Intense } \\
\text { Courtship Bout (seconds) }\end{array}$ & $56.4 \pm 5.8(20)$ & $43.1 \pm 6.1(18)$ & $35.2 \pm 6.1(18)$ & 2,55 & 3.33 & 0.044 \\
\hline $\begin{array}{l}\text { Duration of Copulation } \\
\text { (seconds) }\end{array}$ & $782.2 \pm 103.6(16)$ & $718.6 \pm 110.7(14)$ & $628.3 \pm 107.0(15)$ & 2,44 & 0.537 & 0.588 \\
\hline Number of Eggs & $16.0 \pm 3.7(8)$ & $22.0 \pm 4.7(5)$ & $23.7 \pm 4.0(7)$ & 2,19 & 1.09 & 0.4 \\
\hline
\end{tabular}


Table 8. Analyses of successful courtship and egg sac production for Pardosa milvina treated with atrazine utilizing a Fisher's Exact test.

\begin{tabular}{lrrrr}
\hline \multicolumn{1}{c}{ Metric } & \multicolumn{1}{c}{ Control } & \multicolumn{1}{c}{ Half Dose } & \multicolumn{1}{c}{ Full Dose } & \multicolumn{1}{c}{ p } \\
\hline Successfully Mated & $16 / 22(72.7 \%)$ & $14 / 20(70 \%)$ & $15 / 21(71.4 \%)$ & 1 \\
Produced an Egg Sac & $8 / 16(50 \%)$ & $5 / 14(35.7 \%)$ & $7 / 15(46.7 \%)$ & 0.75 \\
Produced Second Egg Sac & $0 / 8(0 \%)$ & $0 / 5(0 \%)$ & $4 / 7(57.1 \%)$ & 0.008 \\
\hline
\end{tabular}


Table 9. Results from logistic regressions on individual exposure groups with days a female Pardosa milvina was exposed to atrazine as a predictor of egg sac production.

\begin{tabular}{lcccc}
\hline $\begin{array}{l}\text { Days Female Exposed } \\
\text { Predicting Egg Sac Production }\end{array}$ & n & df & $\mathbf{X}^{\mathbf{2}}$ & $\mathbf{p}$ \\
\hline Control & 16 & 1 & 1.36 & 0.24 \\
Half Dose & 14 & 1 & 0.03 & 0.86 \\
Full Dose & 15 & 1 & 7.06 & 0.008 \\
\hline
\end{tabular}


Table 10. Results of a two-way ANOVA on egg sac mass produced by Pardosa milvina comparing spiders treated with atrazine against controls with exposure and egg count as factors. A total of 20 egg sacs were produced and used in the analysis ( 8 from the control group, 5 from the half dose group, and 7 from the full dose group).

\begin{tabular}{lrrr}
\hline \multicolumn{1}{c}{ Model Features } & df & F & p \\
\hline Exposure and Egg Count Predicting Sac Mass & & & \\
Model & 3,19 & 24.46 & $<0.001$ \\
Exposure & 2 & 5.64 & 0.014 \\
Egg Count & 1 & 48.6 & $<0.001$ \\
\hline
\end{tabular}



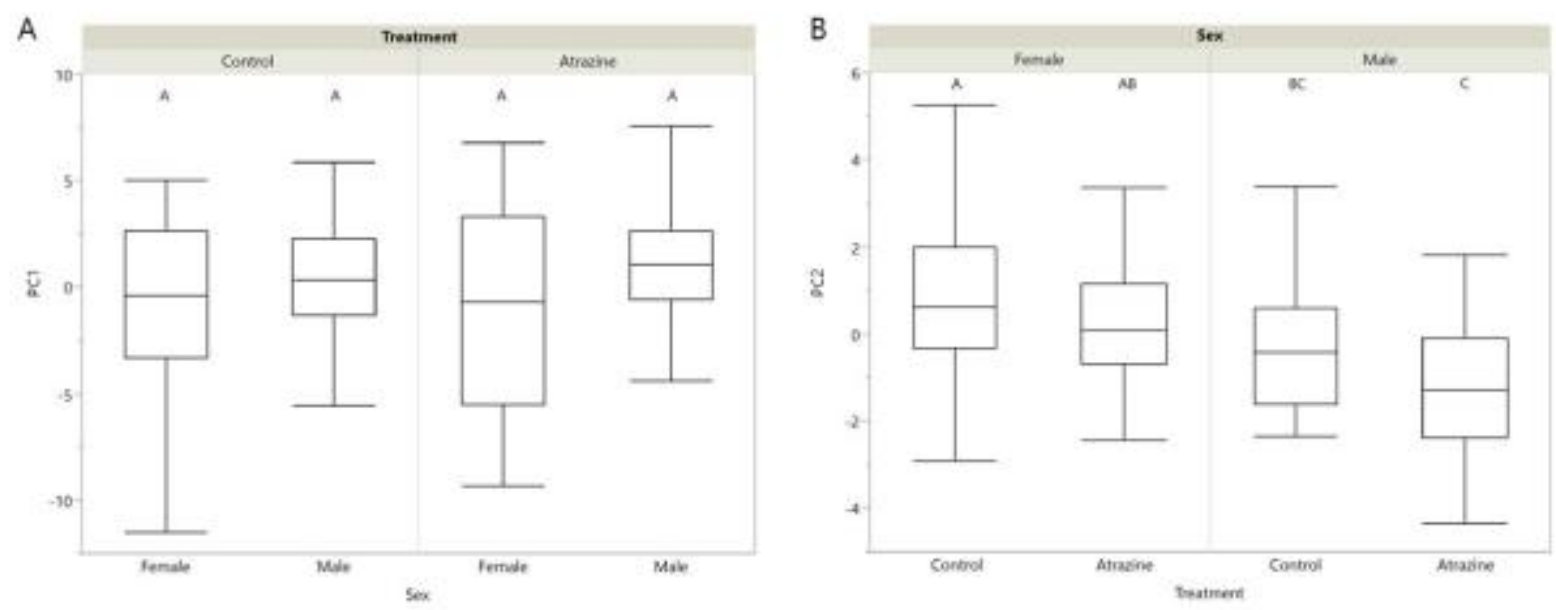

Figure 1. Principal component 1 loadings (A) and principal component 2 loadings (B) for Pardosa milvina treated with atrazine compared to control animals categorized by exposure and sex. The control group and exposure group consisted of 25 males and 25 females each. Box plots display the minimum and maximum, first and third quartile, and the median. Different letters above the boxplots indicate a significant difference based on Tukey-Kramer HSD post hoc analysis. 

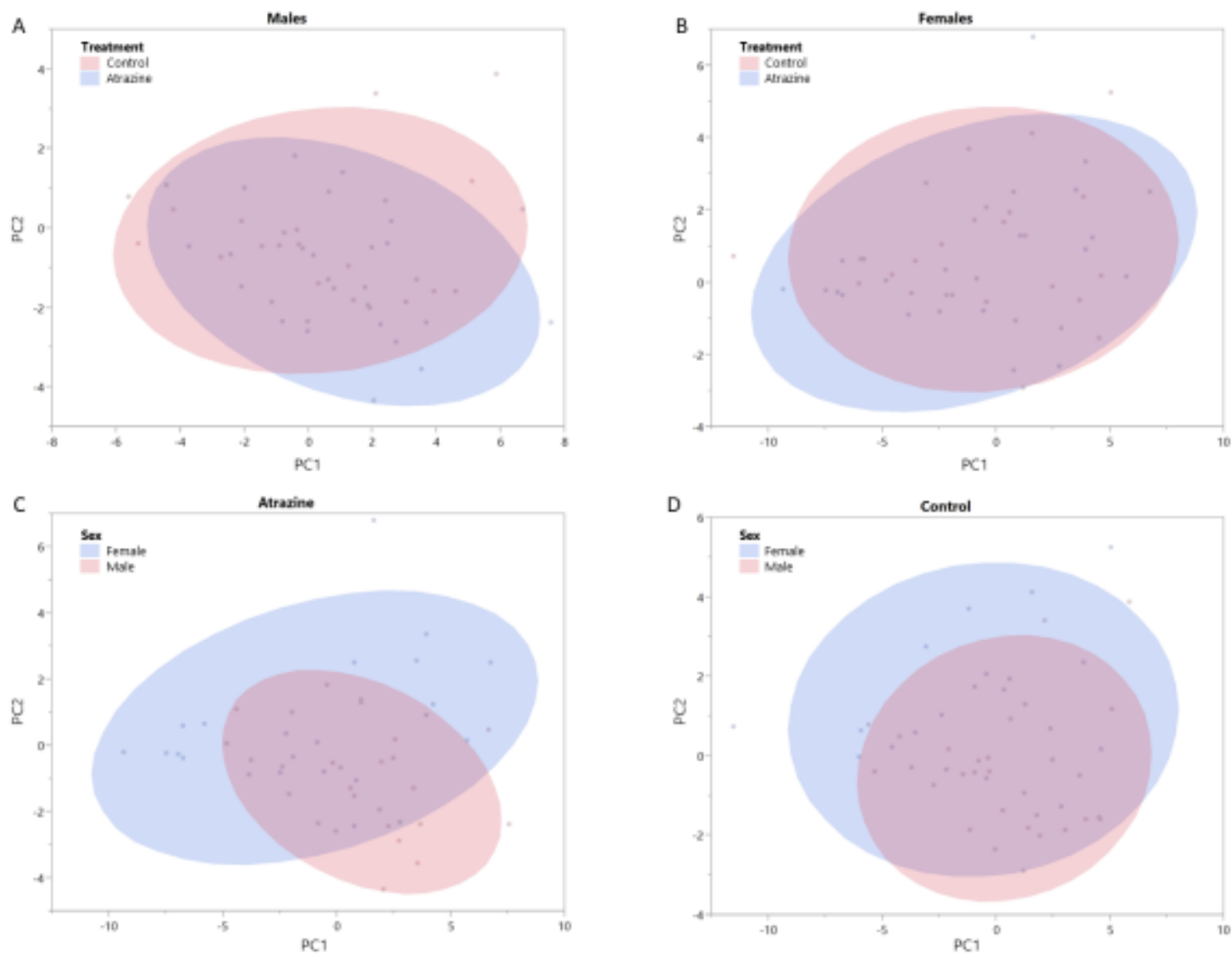

Figure 2. Clustering of the first two principal component loadings for Pardosa milvina treated with atrazine compared to control animals categorized by sex (A and B), as well as clustering of loading for females compared to males categorized by treatment (C and D). The control group and exposure group consisted of 25 males and 25 females each. 

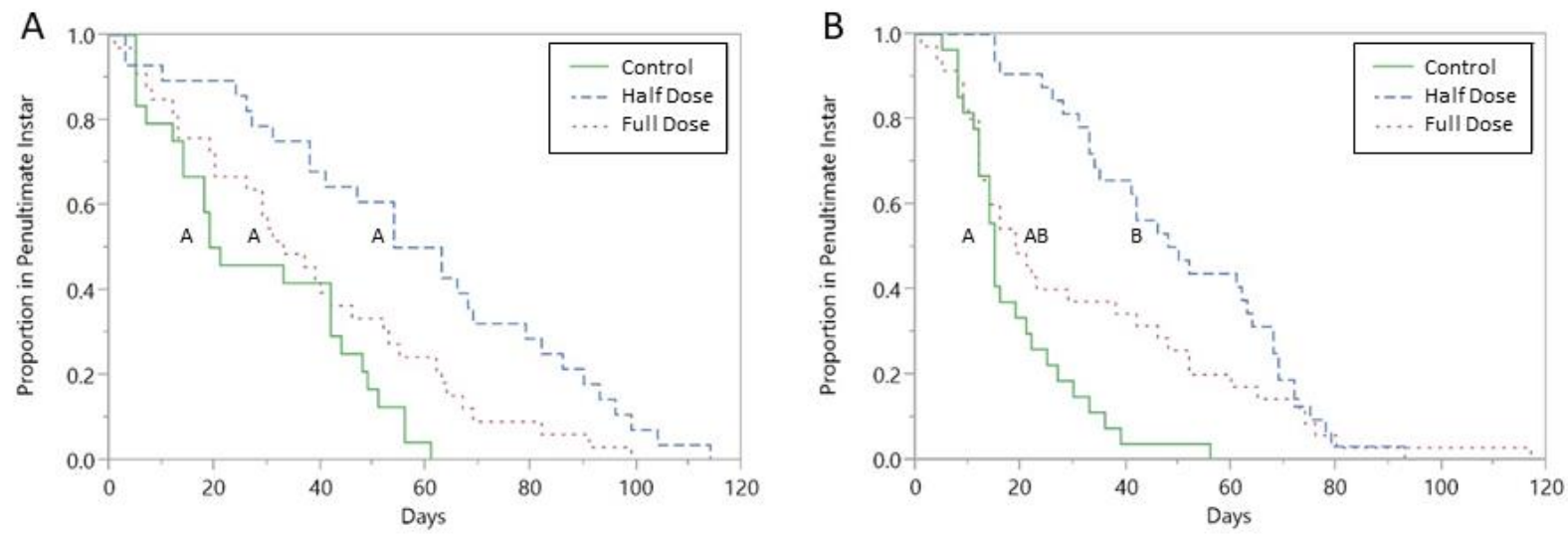

Figure 3. Timing of the ultimate molt in female (A) and male (B) Pardosa milvina categorized by exposure. Females took longer on average to complete the ultimate molt, while exposure to atrazine delayed completion. Different letters associated with individual lines represent significant differences based on pairwise proportional hazard analysis with a Bonferonni correction providing a significance level of $\mathrm{p}=0.017$. 

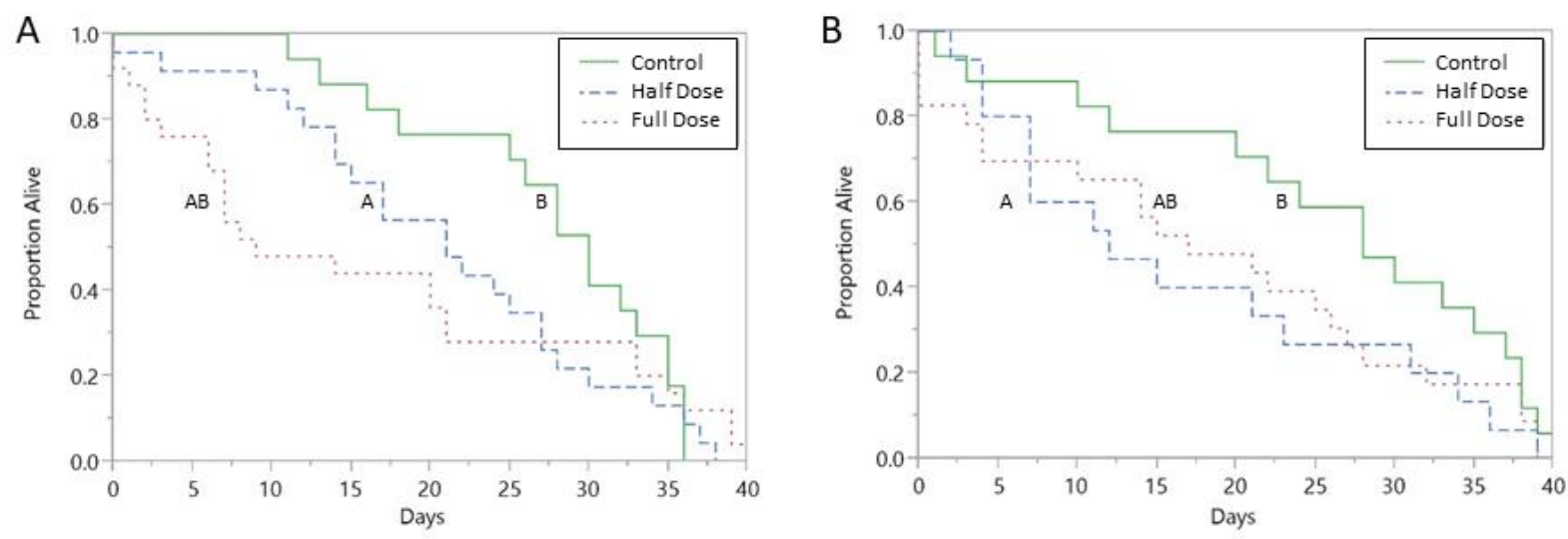

Figure 4. Proportion of female (A) and male (B) Pardosa milvina treated with atrazine surviving over time categorized by exposure. Different letters associated with different lines indicate a significant difference based on pairwise proportional hazards using a Bonferonni corrected significance level of $\mathrm{p}=0.017$. 


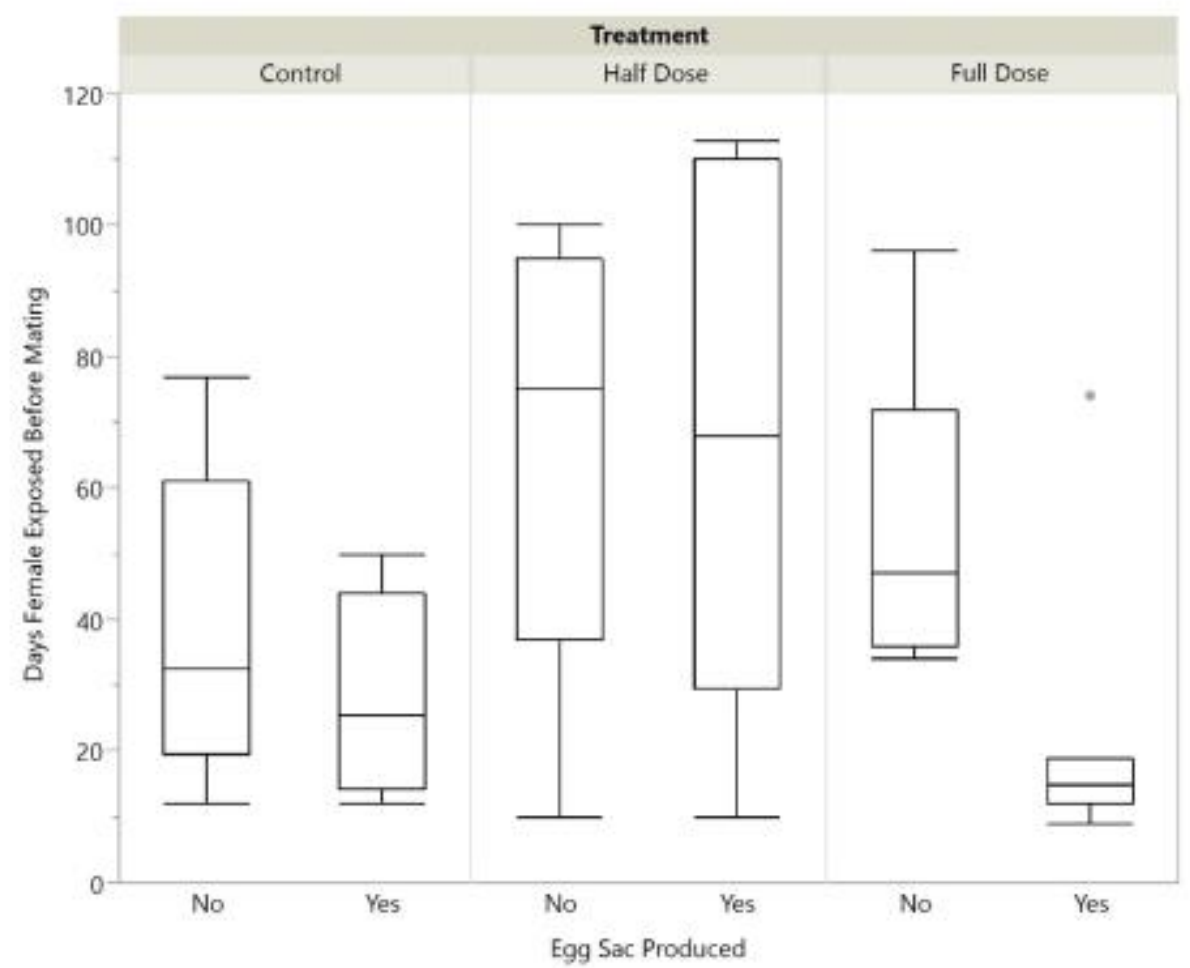

Figure 5. Female Pardosa milvina given the full dose of atrazine were less likely to produce an egg sac the longer she was exposed prior to mating. This relationship did not hold for the control or half dose exposure groups. Box plots display the minimum and maximum, first and third quartile, and the median. Groups consisted of 9 females in control, 5 in half dose, and 7 in full dose. 
Jake Godfrey

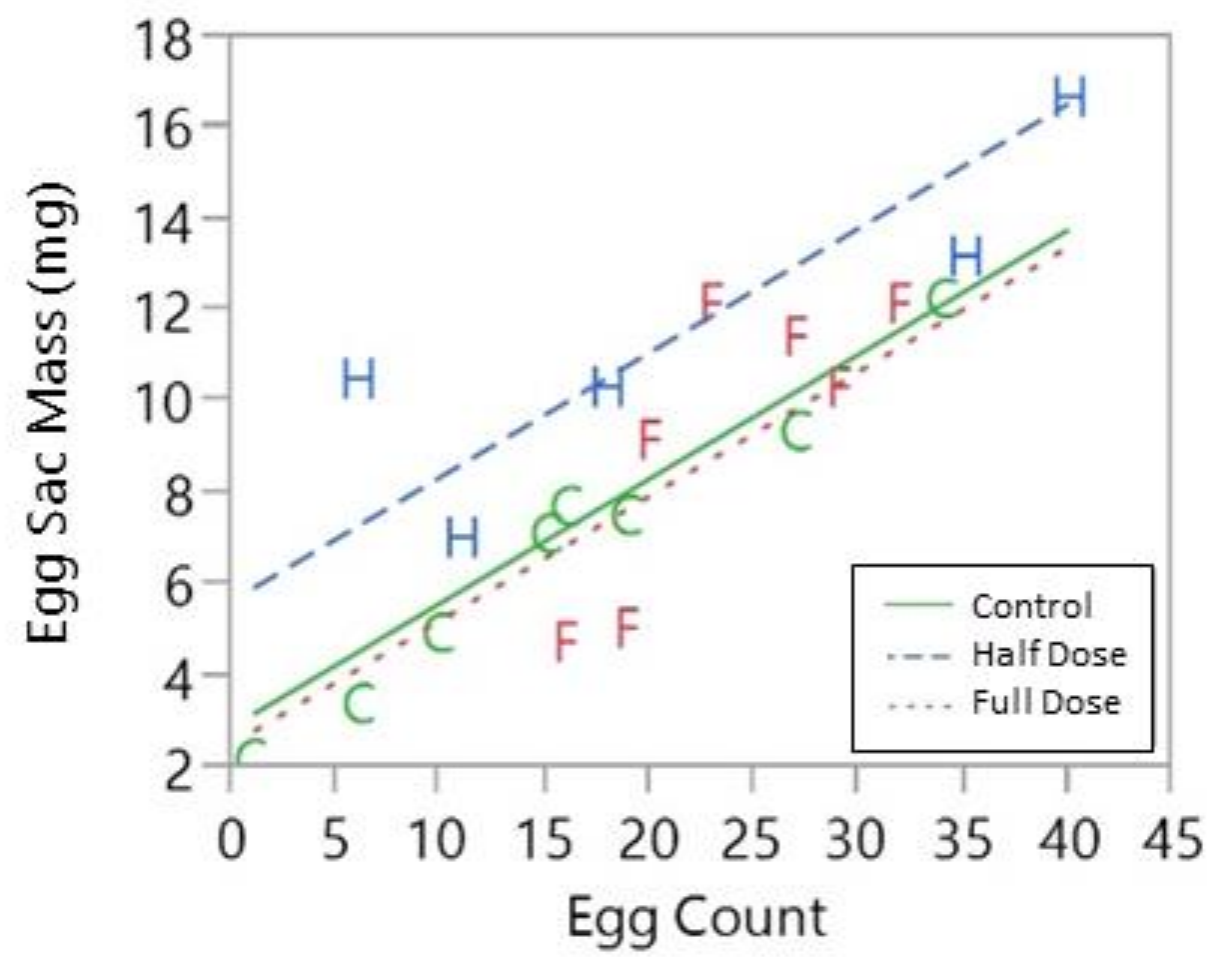

Figure 6. Mass of egg sacs produced by Pardosa milvina categorized by atrazine dosage. Letters correspond to individual data points of an exposure group ( $\mathrm{C}$ for the control group, $\mathrm{H}$ for half dose, and $\mathrm{F}$ for full dose). 